Supporting Information for

\title{
Self-assembled nanotubes that reversibly bind acetic acid guests.
}

\author{
Linda S. Shimizu, * Andrew D. Hughes, Mark D. Smith, Matthew J. Davis, Paul Zhang, \\ Hans-Conrad zur Loye, Ken D. Shimizu \\ Department of Chemistry and Biochemistry, University of South Carolina, Columbia, SC \\ 29208
}

\section{Experimental.}

Materials and Methods. All of the chemicals were purchased from Aldrich and used without further purification. The X-ray powder diffraction data were collected on a Rigaku Dmax-2100 powder X-ray diffractometer using a Bragg-Brentano geometry with $\mathrm{CuK} \alpha$ radiation. The calculated PXRD patterns were produced using the PowderCell for Windows Version 2.3 program and the single crystal reflection data. Guest desorption studies were conducted on a TA Instruments SDT-2960 simultaneous DTA-TGA at a heating rate of $1{ }^{\circ} \mathrm{C} / \mathrm{min}$ from 30 to $150{ }^{\circ} \mathrm{C}$ under Helium. NMR spectra were recorded on a Varian Mercury 300 or $400 \mathrm{MHz}$ NMR or a Varian Inova 500 NMR Spectrometer.

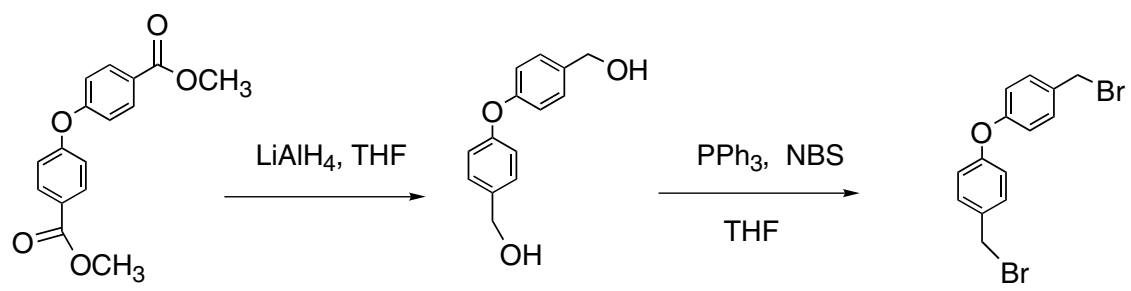

4,4' Oxybis (benzyl alcohol)

Lithium aluminum hydroxide $(3.98 \mathrm{~g}, 105 \mathrm{mmol})$ was stirred at $0^{\circ} \mathrm{C}$ in $100 \mathrm{ml}$ of freshly distilled tetrahydrofuran (THF). 4,4' Oxybis (methyl benzoate) (15.0627g, 52 $\mathrm{mmol}$ ) dispersed in $600 \mathrm{ml}$ of freshly distilled THF was added dropwise to the reaction flask. An extra $100 \mathrm{ml}$ THF was used to wash the 4,4' Oxybis (methyl benzoate) into the reaction flask. The reaction was quenched after 3 days with $8 \mathrm{ml}$ of $\mathrm{H}_{2} \mathrm{O}$, then $8 \mathrm{ml}$ of $1 \mathrm{~N}$ $\mathrm{NaOH}$, filtered and reduced in vacuo to $200 \mathrm{ml}$. The solution was diluted with $400 \mathrm{ml}$ $1 \mathrm{~N} \mathrm{HCl}$ and extracted with ethyl acetate $(3 \times 200 \mathrm{ml})$. The combined organic layers were washed with $1 \mathrm{~N} \mathrm{HCl}(200 \mathrm{ml}), \mathrm{DI} \mathrm{H}_{2} \mathrm{O}(200 \mathrm{ml})$, brine $(1 \times 200 \mathrm{ml})$, and then dried with anhydrous $\mathrm{MgSO}_{4}$. The solution was reduced in vacuo to a white solid. $91 \%$ yield. $\mathrm{mp}$ $131{ }^{\circ} \mathrm{C} .{ }^{1} \mathrm{H}$ NMR (400 MHz, DMSO) $\delta 7.30(4 \mathrm{H}, \mathrm{d}, \mathrm{J}=8.6 \mathrm{~Hz}), 6.92(4 \mathrm{H}, \mathrm{d}, \mathrm{J}=8.6 \mathrm{~Hz})$, 5.16(2H, br. S), 4.45(4H, s) ppm; ${ }^{13} \mathrm{C} \mathrm{NMR}\left(75 \mathrm{MHz}, \mathrm{CDCl}_{3}\right) \delta 33.175,119.094$, 130.655, 132.864, 156.852; IR 3367, 2948, 2886, 1902, 1722, 1602, 1507, 1418, 1264, $1216,1197,1167,1104,1000,839.7,789.3,579.6,533.4,498.5$. 
4,4' Oxybis (benzyl bromide)

4,4' Oxybis (benzyl alcohol) (4g, $17.4 \mathrm{mmol})$ was stirred in freshly distilled THF (100 $\mathrm{ml}$ ) and cooled in a dry ice/ acetone bath to $-20^{\circ} \mathrm{C}$. Triphenylphosphine $(9.104 \mathrm{~g}, 34.7$ $\mathrm{mmol}$ ) and NBS (6.496g, $36.5 \mathrm{mmol})$ were added one at a time to the reaction flask, after which the mixture turned yellow. The reaction was let to warm to room temperature and was quenched 4 days later with $\mathrm{NaHCO}_{3}$ (saturated aq., $125 \mathrm{ml}$ ) and extracted with $\mathrm{CH}_{2} \mathrm{Cl}_{2}$. The organic layers were washed with brine $(250 \mathrm{ml})$, and then dried with anhydrous $\mathrm{MgSO}_{4}$. The solution was reduced in vacuo to a light pink powder. Product was purified with column chromatography (1:1 chloroform:hexane). $69 \%$ yield. $\mathrm{mp} 92{ }^{\circ} \mathrm{C} .{ }^{1} \mathrm{H} \mathrm{NMR}\left(400 \mathrm{MHz}, \mathrm{CDCl}_{3}\right) \delta 7.36(4 \mathrm{H}, \mathrm{d}, \mathrm{J}=8.5 \mathrm{~Hz}), 6.98(4 \mathrm{H}, \mathrm{d}, \mathrm{J}=8.5 \mathrm{~Hz})$, $4.51(4 \mathrm{H}, \mathrm{s}) \mathrm{ppm} ;{ }^{13} \mathrm{C} \mathrm{NMR}\left(75 \mathrm{MHz}, \mathrm{CDCl}_{3}\right) \delta 64.882,118.915,128.704,135.813$, 156.755; IR 1596, 1499, 1440, 1199, 1161, 1088, 1016, 861, 840, 722, 595, 525, 482.

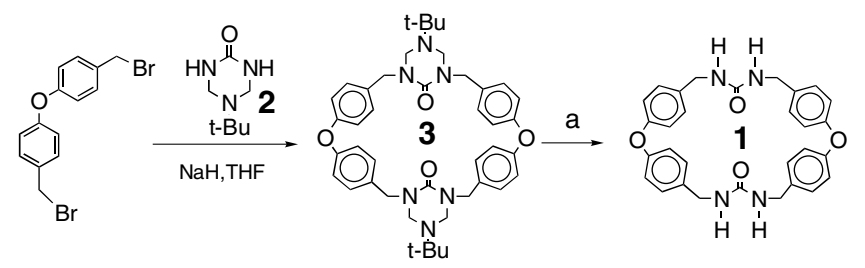

$t$-butyl triazone (2) was synthesized according to the literature procedures. ${ }^{1}$

Protected cyclic diurea (3)

$2(1.00 \mathrm{~g}, 6.39 \mathrm{mmol})$ and $\mathrm{NaH}(1.01 \mathrm{~g}, 25 \mathrm{mmol})$ were refluxed in freshly distilled THF (125 ml) for $0.5 \mathrm{hr}$. 4,4' Oxybis (benzyl bromide) $(2.27 \mathrm{~g}, 6.4 \mathrm{mmol}$ ) was then added to the reaction flask. The reaction was quenched 3 days later with $1 \mathrm{~N} \mathrm{HCl}(5 \mathrm{ml})$ and diluted with $\mathrm{H}_{2} \mathrm{O}(20 \mathrm{ml})$. The dispersion was reduced in vacuo to $\sim 30 \mathrm{ml}$. The solution was diluted with $1 \mathrm{~N} \mathrm{HCl}(20 \mathrm{ml})$ and $\mathrm{H}_{2} \mathrm{O}(50 \mathrm{ml})$ and extracted with $\mathrm{CHCl}_{3}$ $(2 \times 100 \mathrm{ml})$. The combined organic layers were washed with brine and then dried with anhydrous $\mathrm{MgSO}_{4}$. The solution was reduced in vacuo to a cream colored film. Product was recrystallized from chloroform. $20 \%$ yield. ${ }^{1} \mathrm{H}$ NMR $\left(400 \mathrm{MHz}, \mathrm{CDCl}_{3}\right) \delta 7.31(8 \mathrm{H}$, dd, J=8.4, $2.7 \mathrm{~Hz}), 6.95(8 \mathrm{H}, \mathrm{dd}, \mathrm{J}=8.4,2.9 \mathrm{~Hz}), 4.50(8 \mathrm{H}, \mathrm{s}), 4.22(8 \mathrm{H}, \mathrm{s}), 0.98(18 \mathrm{H}, \mathrm{s})$ ppm; ${ }^{13} \mathrm{C}$ NMR $\left(75 \mathrm{MHz}, \mathrm{CDCl}_{3}\right) \delta 28.313,48.172,54.260,61.484,118.835,129.928$, 133.020, 156.109, 156.502; IR 3432, 2974, 1721, 1636, 1601, 1500, 1436, 1420, 1365, $1305,1232,1163,1121,1099,1013,928,871,845,786,743,649,495$. See CIF file for crystal structure.

\section{Deprotection of $\mathbf{3}$}

$3(103.3 \mathrm{mg}, 0.147 \mathrm{mmol})$ was refluxed in 1:1 [20\% $\left.\mathrm{NH}\left(\mathrm{CH}_{2} \mathrm{CH}_{2} \mathrm{OH}\right)_{2} / \mathrm{H}_{2} \mathrm{O}\right]: \mathrm{MeOH}$ $(10 \mathrm{ml})$. The reaction was cooled the next day, then suction filtered and washed with 10 $\mathrm{ml} 1 \mathrm{~N} \mathrm{HCl}, 10 \mathrm{ml} \mathrm{H}_{2} \mathrm{O}, 10 \mathrm{ml} 1 \mathrm{~N} \mathrm{HCl}$ and $10 \mathrm{ml} \mathrm{H}_{2} \mathrm{O}$. The filtrate was dried in vacuo and recrystallized from acetic acid. The white crystals were further dried in vacuo to drive off guest acetic acid. $80-90 \%$ yield. ${ }^{1} \mathrm{H}$ NMR $\left(300 \mathrm{MHz}, \mathrm{CDCl}_{3}\right) \delta 7.178(8 \mathrm{H}, \mathrm{d}$,

\footnotetext{
${ }^{1}$ Mitchell, A.R.; Pagoria, P. F.; Coon, C.L.; Jessop, E. S.; Poco, J. F.; Tarver, C.M.; Breithaupt, R. D.; Moody, G. L. Propellants, Explos. Pyrotech. 1995, 60, 232.
} 
$\mathrm{J}=8.524 \mathrm{~Hz}), 6.864(8 \mathrm{H}, \mathrm{d}, \mathrm{J}=8.524), 6.543(4 \mathrm{H}, \mathrm{t}, \mathrm{J}=6.324), 4.176(8 \mathrm{H}, \mathrm{d}, \mathrm{J}=5.774) \mathrm{ppm}$; IR $3360,1631,1578,1500,1422,1239,1164,1102,1013,875,809,650,497$. See CIF file for crystal structure.

\section{TGA analysis:}

The TGA experiments were carried out on 5-10 $\mathrm{mg}$ of absorbed sample. The sample was heated at $1{ }^{\circ} \mathrm{C} / \mathrm{min}$ from 30 to $150{ }^{\circ} \mathrm{C}$ under Helium. Upon completion, the sample was collected for the next adsorption-desorption study. The Thermal Gravimetric Analysis (TGA) curve shows a $11.61 \%$ weight loss occurring between 25 and $90{ }^{\circ} \mathrm{C}$ corresponding to a loss of the acetic acid guest (1:1 macrocycle to guest), which was confirmed by NMR. The assembly shows no further weight loss up to a temperature of $150^{\circ} \mathrm{C}$, and the white crystals showed no sign of cracking. We then sought to rebind the acetic acid guest by treatment of the empty self-assembled network with acetic acid vapor. The crystals were exposed to acetic acid vapor in a sealed vessel for 72 hours and then the treated crystals were reexamined by TGA, which showed a similar curve, with an $11.02 \%$ weight loss of rebound acetic acid guest. Repetition of acetic acid guest removal and rebinding has established that the inclusion behavior is reversible and that the channels retain their inclusion ability over time.

\begin{tabular}{|c|c|c|}
\hline $\mathrm{AcOH}$ data table & $\%$ wt. loss & temp. range \\
\hline 1st run & $11.61 \%$ & $30^{\circ} \mathrm{C}-90^{\circ} \mathrm{C}$ \\
\hline 2nd run & $11.02 \%$ & $30^{\circ} \mathrm{C}-90^{\circ} \mathrm{C}$ \\
\hline 3rd run & $11.34 \%$ & $30^{\circ} \mathrm{C}-90^{\circ} \mathrm{C}$ \\
\hline
\end{tabular}

\section{Powder XRD data for 1.}

A sample of $1(50 \mathrm{mg})$ recrystallized from $\mathrm{AcOH}$ was ground to a powder and examined by PXRD (Figure S1). The X-ray powder diffraction data were collected on a Rigaku Dmax-2100 powder X-ray diffractometer using a Bragg-Brentano geometry with $\mathrm{CuK} \alpha$ radiation. The step-scans covered the angular range $2-20^{\circ} 2 \theta$ in steps of $0.05^{\circ} 2 \theta$. For these $50 \mathrm{mg}$ powder samples the data collection to $20^{\circ} 2 \theta$ requires approximately 2 hours. The single crystal data was used to calculate PXRD patterns for the AcOH bound. Not surprisingly, the calculated PXRD for the bound material closely matches the observed PXRD, supporting the hypothesis that the bulk material shows a single phase product that has a similar structure as the single crystal. The guest was then removed by heating to $120^{\circ} \mathrm{C}$ for 1.5 hours and the PXRD data reexamined (Figure S2). For the evacuated solid a PXRD was calculated simply by omitting the acetic acid guests from the single crystal X-ray structure. Gratifyingly, again this calculated structure is very close to the experimentally observed PXRD of the empty assembly, supporting the hypothesis that the evacuated network is structurally similar to the filled network and that the matrix maintains its integrity with empty channels. Finally the evacuated solid was exposed to acetic acid vapor in a sealed vessel for 72 hours and the PXRD reexamined. 


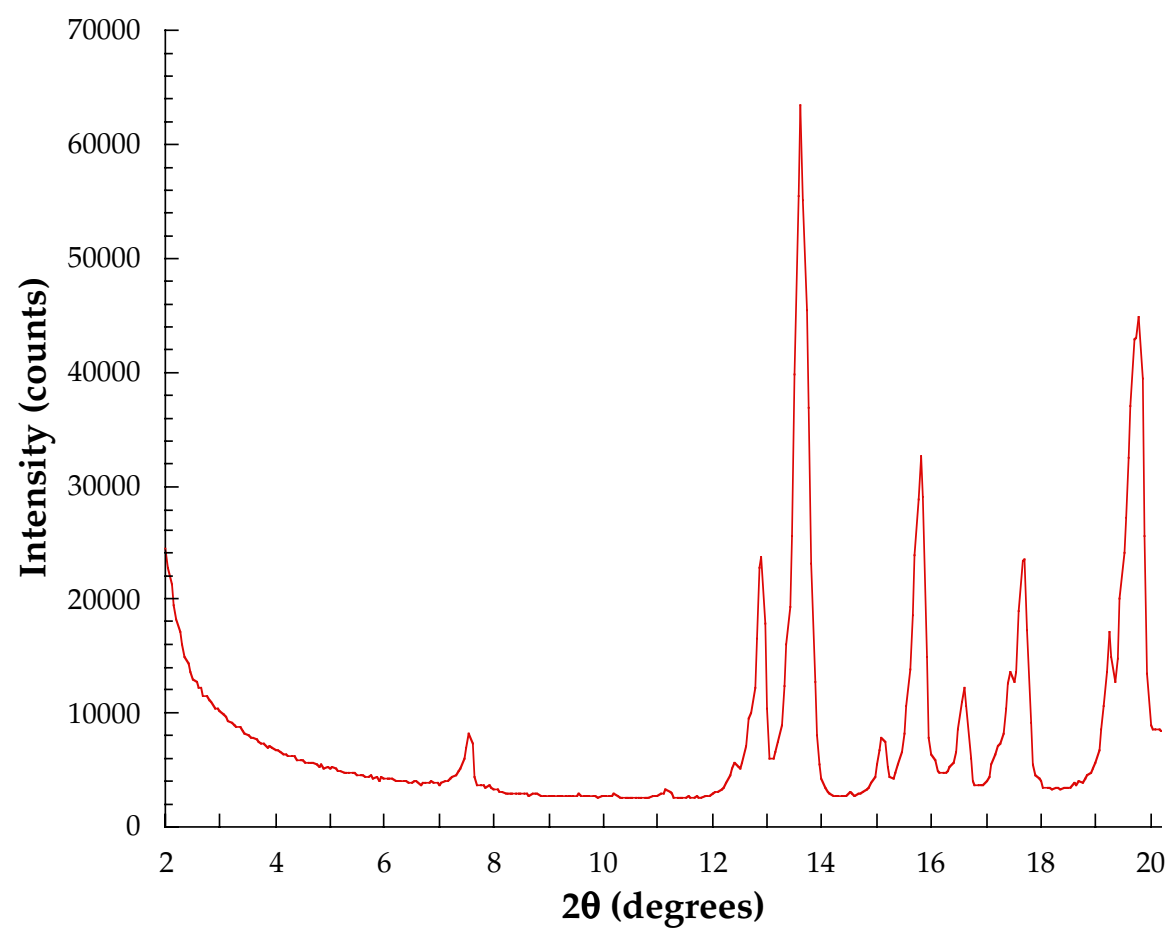

Figure S1. Observed PXRD of 1 with bound acetic acid guest.

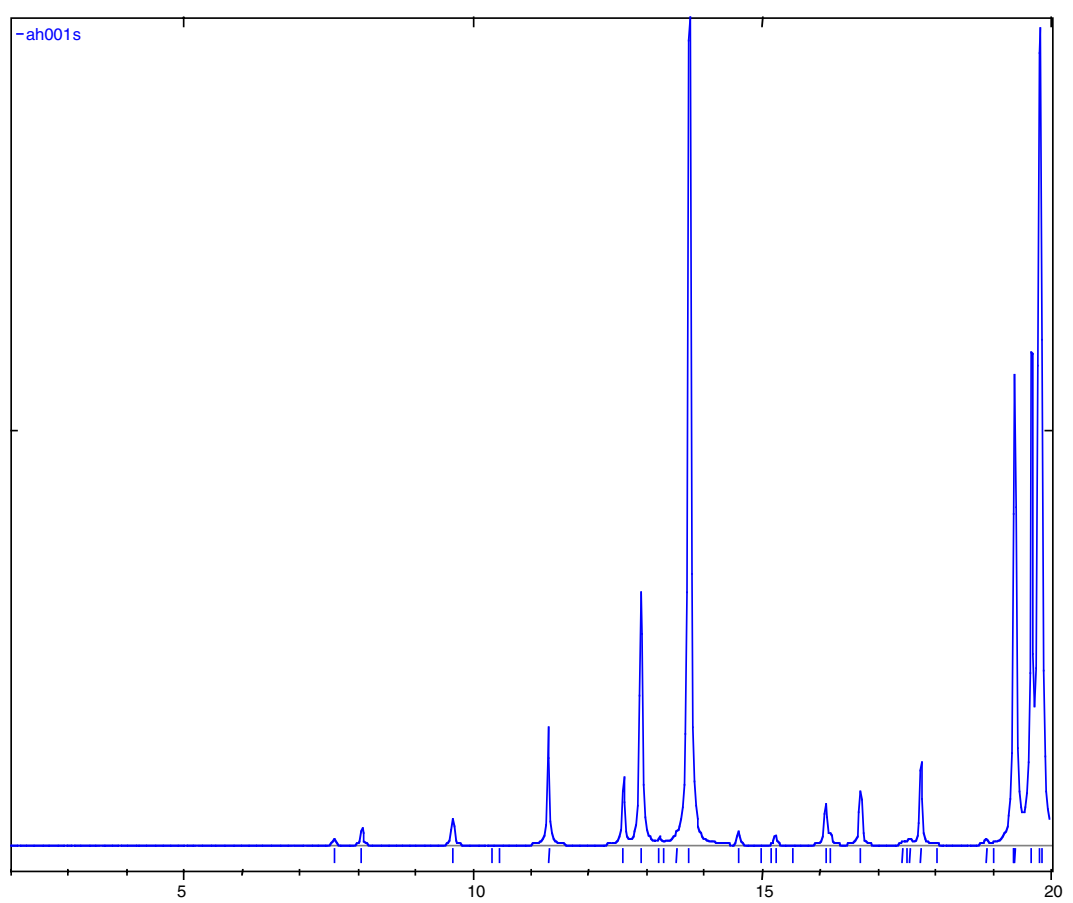

Figure S2. Simulated PXRD of $\mathbf{1}$ with bound acetic acid guest. 


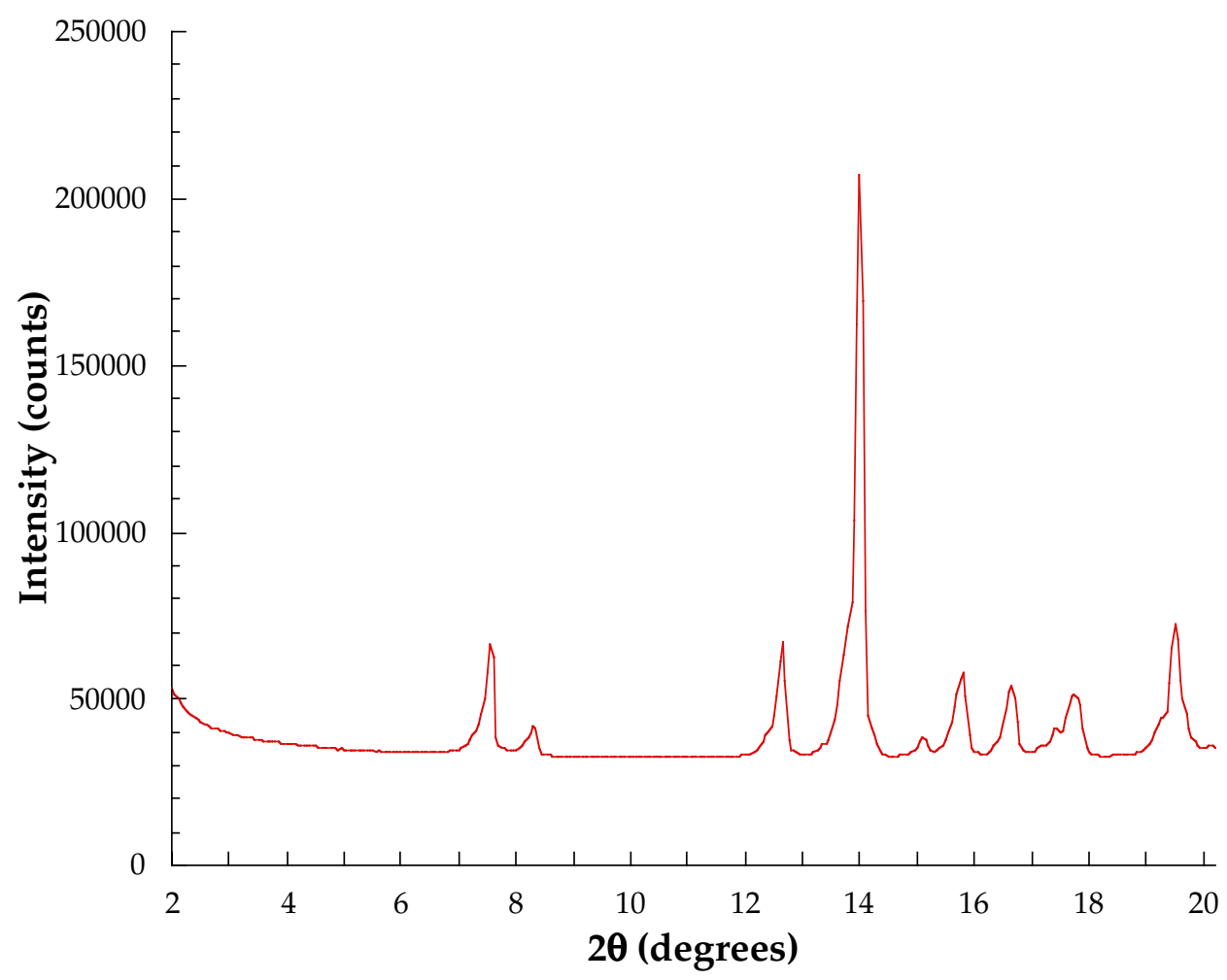

Figure S3. Observed PXRD of 1 in the absence of guest 


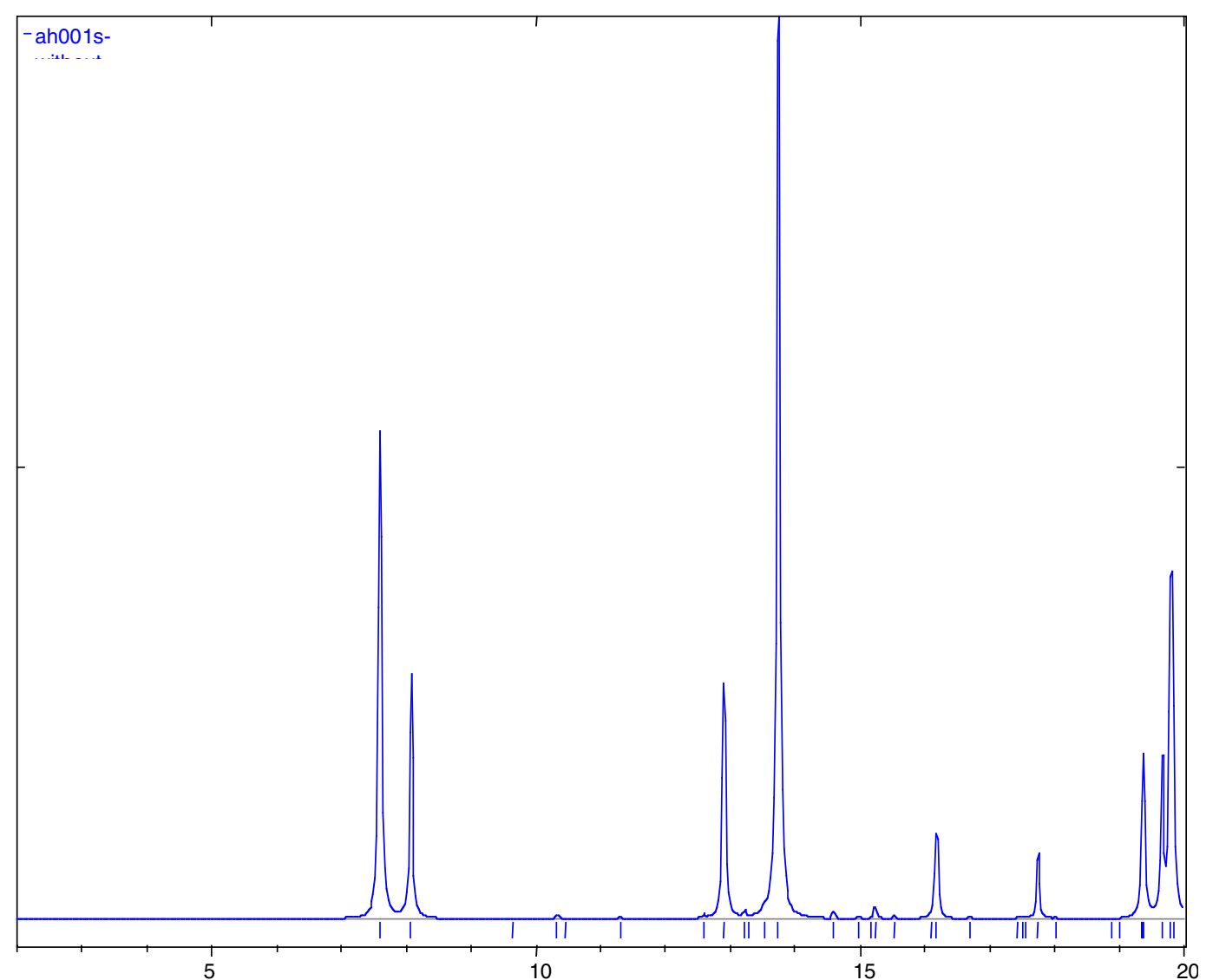

Figure S4. Simulated PXRD of 1 in the absence of guest. 

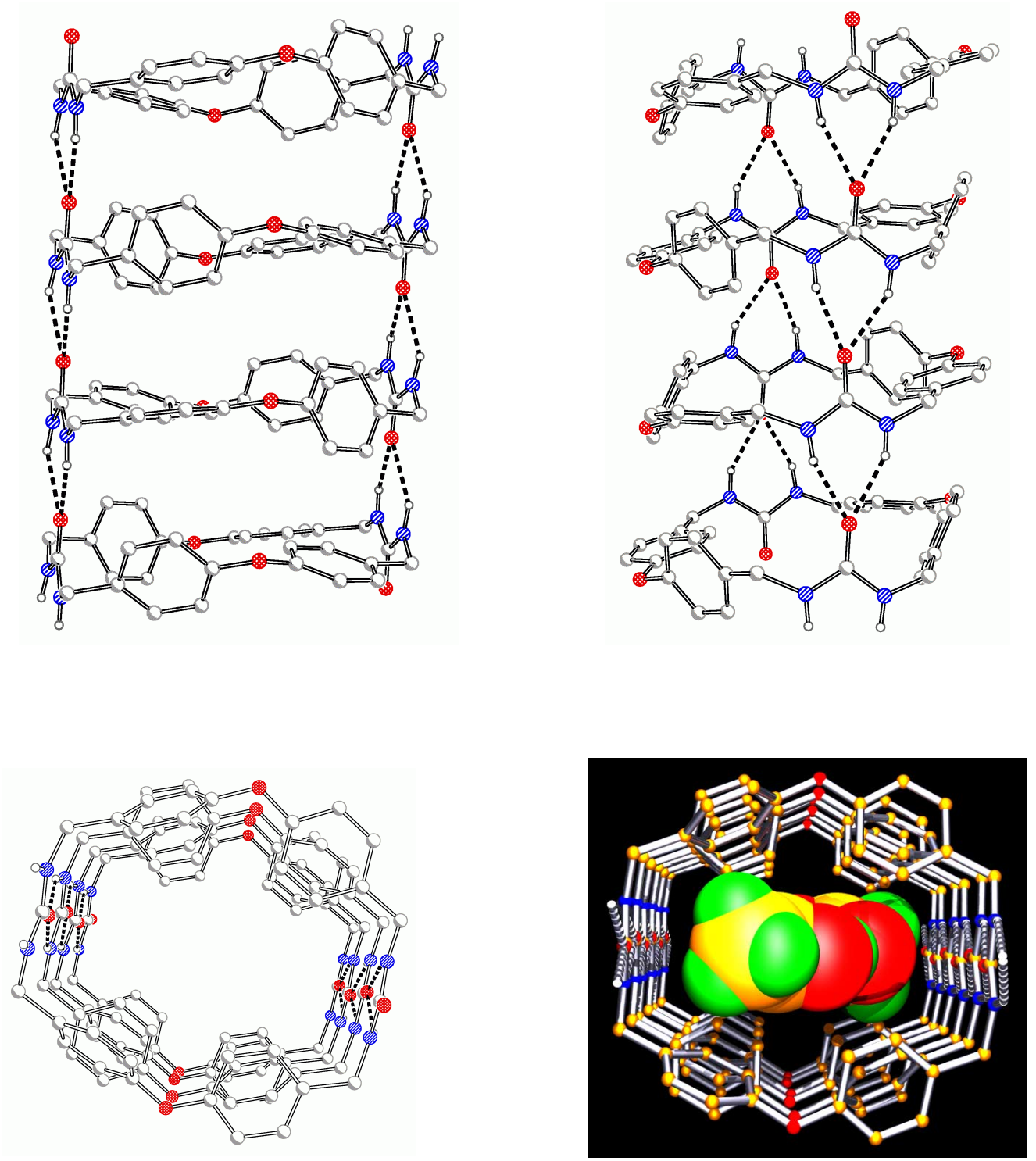

Figure S6. A scheme showing the hydrogen bonded columns down the [100] axis 